\title{
Microvideos como herramienta docente en Química General
}

\author{
Sergio Armenta, Francesc Albert Esteve-Turrillas
}

Departamento de Química Analítica, Universitat de València, Edificio Jeroni Muñoz, c/ Dr. Moliner 50,46100 Burjassot, España (sergio.armenta@uv.es, francesc.a.esteve@uv.es)

\begin{abstract}
The objective of the present communication is the preparation of short duration videos, less than 2 minutes (microvideos) where the main ideas of the different topics of the subject General Chemistry would be summarized in a fashion way, enhancing the teaching/learningn process. The development of the videos must be done by the students to fix the main concepts of the lectures and to acquire transversal key competences such as collaborative learning, problem solving skills, self-directed learning and organizative and technologic skills.The obtained results can be considered as preliminar reults, because of effectivity has been evaluated qualitatively. To obtain more realistic conclusions, the activity should be performed next years and use control groups to quantitatively evaluate the impact of this activity on the teaching/learning process.
\end{abstract}

Keywords: microvideos, digital tools, colaborative learning, problema solving, self-directed learning.

\begin{abstract}
Resumen
El objetivo del presente trabajo es la elaboración de videos de corta duración, inferior a 2 minutos (microvideos) en los que se resuma, de una forma atractiva, las principales ideas de diferentes temas de la asignatura Química General II, facilitando el proceso de enseñanza/aprendizaje. La creación de los videos de aprendizaje corre a cargo de los estudiantes para profundizar no solamente en los conceptos teóricos de la asignatura sino también para la adquisición de competencias transversales como serían el trabajo colaborativo, resolución de problemas, aprendizaje autónomo así como competencias tecnológicas y organizativas. Los resultados obtenidos son preliminares, por lo que se han obtenido datos de efectividad meramente cualitativos. Para extraer conclusiones mas realistas, se desarrollará esta actividad en cursos futuros así como se usarán grupos control en los que no se aplique esta herramienta. De esta forma se podrá evaluar cuantitativamente su impacto a largo plazo en el proceso de enseñanza/aprendizaje.
\end{abstract}

Palabras clave: microvideos, herramientas digitales, trabajo colaborativo, resolución de problemas, trabajo autónomo. 


\section{Introducción}

La teoría de Howard Gardner, llamada teoría de las Múltiples Inteligencias (MI), (Gardner, 1983), define inteligencia como una mezcolanza de diferentes habilidades o aptitudes que incluyen musical, lingüística, lógica-matemática, espacial, interpersonal, intrapersonal, natural, kinestésica y existencial. Gardner ubica el término inteligencia dentro de un contexto social "la habilidad para resolver problemas, o para crear productos, que tengan un valor o utilidad en un determinado escenario".

En este sentido, está claro que los avances tecnológicos han cambiado la forma de actuarpensar-vivir de la sociedad actual. El modo de vida actual esta basado en las premisas más rápido, más cerca, más accesible,... A medida que la tecnología avanza, lo hace también la demanda de un nivel de accesibilidad instantánea de los usuarios. El mundo se ha convertido en un mundo digital y las aulas están siguiendo el mismo camino. La forma de enseñar y aprender no son ajenas a dicho cambio. El profesor continua siendo el punto de atención, pero ahora se disponen de nuevos y numerosos recursos.

El viejo cliché "una imagen vale más que mil palabras" se hace cada vez más una realidad. Las imágenes, y en mayor grado los videos, añaden autenticidad y realidad al contexto pedagógico. Las imágenes y los videos han sido una herramienta pedagógica desde hace mucho tiempo, como Anuli Akanegbu describe en EDTECH MAGAZINE desde el empleo de la "linterna mágica" hasta las recientes tecnologías basadas en visualizaciones en streaming.

Por tanto, el motivo principal de esta propuesta es destacar la importancia del video con motivos educativos y adaptar las características de dichos videos a las exigencias de la sociedad/estudiante actual.

En este proyecto, nos centraremos en la realización de videos como material suplementario a las clases magistrales. Este tipo de videos se usan generalmente al principio de un tema para proporcionar al estudiante el contexto o background del conocimiento, o al final del tema como material suplementario para reforzar los conocimientos adquiridos.

Desde hace tiempo se ha hecho hincapié y discutido ampliamente en el empleo y la preparación por parte de los profesores del video como herramienta pedagógica. Sin embargo, tal y como describe Allam (2006), parece evidente que el desafio pedagógico para los alumnos de crear imágenes y videos para ser usados en términos pedagógicos además de resultar atractivo y útil, permite que los estudiantes adquieran competencias transversales, entre las que cabría destacar habilidades de búsqueda científica, trabajo colaborativo, resolución de problemas, así como competencias tecnológicas y organizativas. Desde el punto de vista pedagógico, el foco está en el estudiante que se convierte en creador de conocimiento. En este sentido, se debe considerar igual de importante el proceso de creación como el objeto creado.

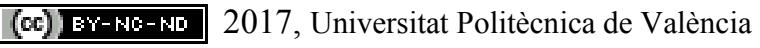


Las principales características que debe tener el video creado se enumeran a continuación:

- La duración del video debe ser corta (inferior a 2 minutos) debido a que la atención de los estudiantes es limitada cuando se observan contenidos visuales. Es preferible dividir los videos en dos con actividades focalizadas.

- Los videos deben estar disponibles para ser visualizados fuera de clase, por tanto, se debe proporcionar una página web o link para que los estudiantes puedan ver el video cuando quieran y tantas veces como consideren oportuno.

En cuanto a la asignatura de Química General II decir que se imparte en el segundo cuatrimestre del primer curso del grado en Química. El número de estudiantes matriculados es de 220-240 divididos en cuatro grupos de 60 estudiantes aproximadamente. Respecto a los resultados académicos cabe destacar que el porcentaje de estudiantes aprobados respecto a matriculados es de 54\% en el periodo comprendido entre 2010-11 y 2015-2016, siendo el 57.9\% el correspondiente al año 2015-2016.

\section{Objetivos}

El principal objetivo del presente trabajo es la elaboración de videos de corta duración, inferior a 2 minutos (microvideos) en los que se resuma, de una forma atractiva, las principales ideas de diferentes temas de la asignatura Química General II, facilitando el proceso de enseñanza/aprendizaje. La creación de los videos de aprendizaje corre a cargo de los estudiantes para profundizar no solamente en los conceptos teóricos de la asignatura sino también para la adquisición de competencias transversales como serían el trabajo colaborativo, resolución de problemas, aprendizaje autónomo así como competencias tecnológicas y organizativas.

\section{Desarrollo de la innovación}

Esta tarea se ha realizado siguiendo el esquema propuesto:

- Clases magistrales participativas (dependiendo del tema seleccionado el número de sesiones puede variar entre 3-6).

- Seminario, donde el docente ha comunicado a los estudiantes en que consiste el trabajo, se definen claramente los objetivos, se realiza un reparto del tiempo y los papeles de cada miembro del grupo (selección de conceptos teóricos que deben aparecer en el video, escritura del guión, grabación y edición del video y dirección) y definición clara de los resultados esperados y la evaluación.

- Tutorías grupales (mínimo 2/3 sesiones), seguimiento del proceso de realización del video.

- Seminario, visionado y evaluación de la actividad realizada.

En cada una de las sesiones de trabajo, tanto las que se han realizado en presencia del profesor como las que no, se han redactado actas de reunión, para facilitar el seguimiento y 
la evaluación del proceso. Dicha acta incluye fecha, asistentes, acuerdos y actividades futuras.

La evaluación es un aspecto particularmente relevante para asegurar el cumplimiento de la actividad propuesta. Dicha evaluación se realizará mediante el uso de rúbricas analíticas, un instrumento cuya principal finalidad es compartir los criterios de realización de las tareas de aprendizaje y de evaluación con los estudiantes y entre el profesorado. De esta forma se pretende que los alumnos sean conocedores de los diferentes niveles de cumplimiento de la actividad o de parte de ella, desde el menos aceptable hasta la resolución ejemplar, desde lo considerado como insuficiente hasta lo excelente.

Se pretende que los estudiantes puedan autoevaluarse y que el feedback sea casi inmediato, permitiendo a los estudiantes conocer el resultado de su trabajo en base a estándares conocidos previamente al desarrollo de la tarea.

Adicionalmente, se han realizado encuestas tanto a los estudiantes como a los docentes para establecer el grado de satisfacción correspondiente al desarrollo de la actividad y de los materiales elaborados.

\section{Resultados}

A continuación se muestran parte de los resultados obtenidos durante la preparación del material definitivo en el grupo D de la asignatura de Química General II del Grado en Química el año 2016-17. El número de alumnos implicados en la actividad fue de 40, distribuidos en grupos (8) de 4-5 miembros.

En la actividad desarrollada, cada grupo preparó un microvideo de 2 minutos de duración en el que se resumen los aspectos más importantes de cada uno de los temas implicados en la asignatura. En el caso de Química General II los temas son los siguientes:

Tema 1. Energía de las reacciones químicas

Tema 2. La dirección del cambio químico

Tema 3. El equilibrio en las reacciones químicas

Tema 4. Cambios de estado de sustancias puras

Tema 5. Disoluciones

Tema 6. Equilibrio ácido-base

Tema 7. Equilibrios de formación de complejos

Tema 8. Equilibrios de solubilidad

Tema 9. Equilibrios de oxidación-reducción

Tema 10. La velocidad del cambio químico

(cc) EY-NC-ND 2017, Universitat Politècnica de València 
Para la elaboración de los videos por parte de los estudiantes se utilizaron programas para la edición y creación de presentaciones como el VIDEOSCRIBE, TRUSCRIBE, POWTOON, GOANIMATE, y VIDEOMARKERFX entre otros.

En la Figura 1 se adjuntan diferentes capturas de pantalla obtenidas de los videos creados por los estudiantes de Química General II, grupo D, año 2016-2017.
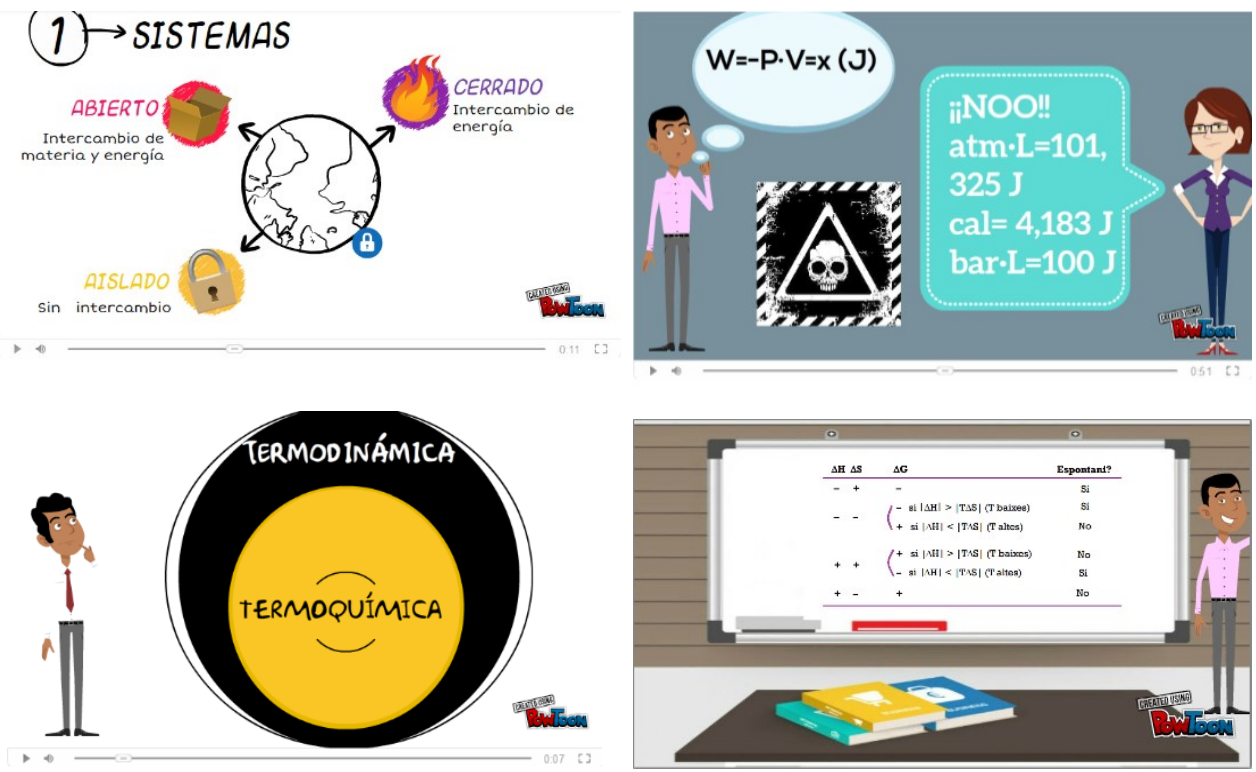

Fig. 1 Capturas de pantalla de los videos realizados por los estudiantes de Quimica General II, grupo D, 20162017.

Los resultados de aprendizaje que aparecen en la guía docente y que se pretenden desarrollar y evaluar con la actividad propuesta son:

1. Realizar una distribución de tareas que permita el correcto desarrollo del trabajo en equipo.

2. Realizar una correcta planificación de las tareas que permita realizarlas puntualmente.

3. Saber gestionar los conflictos que puedan surgir con aportación de ideas al colectivo y con responsabilidad compartida.

4. Justificar y debatir con argumentos racionales hechos científicos de manera adecuada y rigurosa.

La evaluación de dicha actividad forma parte de la evaluación de las sesiones de tutorías grupales, seminarios, elaboración de trabajos y/o exposiciones orales y se ha realizado mediante el empleo de rúbricas diseñadas para ello (ver Figura 2). El porcentaje en el que la

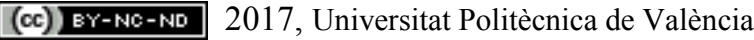


actividad expuesta contribuye a la nota final es un $25 \%$, que se obtendrá de la siguiente forma:

Evaluación del proceso (50\%). Esta nota se obtiene como media de la evaluación del profesor y la autoevaluación del propio grupo.

Evaluación del resultado (50\%). Esta nota se obtiene como media de la evaluación del profesor y la evaluación del resto de grupos (compañeros de clase).

Rúbrica objeto para aprendizaje cooperativo- video Química General II

Prof. Sergio Armenta

Grupo

\begin{tabular}{|l|l|l|l|l|l|}
\hline \multicolumn{1}{|c|}{ CATEGORIA } & $\mathbf{4}$ & $\mathbf{3}$ & $\mathbf{1}$ & NOTA \\
\hline $\begin{array}{l}\text { CONCEPTOS } \\
\text { TEÓRICOS }\end{array}$ & $\begin{array}{l}\text { Todos los conceptos teóricos } \\
\text { importantes han sido } \\
\text { plasmados. }\end{array}$ & $\begin{array}{l}\text { La mayor parte de los } \\
\text { conceptos teóricos } \\
\text { importantes han sido } \\
\text { plasmados. }\end{array}$ & $\begin{array}{l}\text { Alguno de los conceptos } \\
\text { teóricos importantes ha } \\
\text { sido plasmado. }\end{array}$ & $\begin{array}{l}\text { No se han plasmado los } \\
\text { conceptos teóricos } \\
\text { importantes }\end{array}$ & \\
\hline EDICIÓN DEL VIDEO & $\begin{array}{l}\text { El vídeo ha sido editado de } \\
\text { forma sobresaliente. }\end{array}$ & El vídeo ha sido editado & $\begin{array}{l}\text { La edición del vídeo es } \\
\text { deficiente }\end{array}$ & El vídeo no ha sido editado & \\
\hline GUIÓN & $\begin{array}{l}\text { El guión del video es } \\
\text { sobresaliente. }\end{array}$ & $\begin{array}{l}\text { El guión del vídeo es } \\
\text { aceptable. }\end{array}$ & $\begin{array}{l}\text { El guión del vídeo es } \\
\text { mejorable. }\end{array}$ & No hay guión. & \\
\hline DIRECCIÓN & $\begin{array}{l}\text { La dirección del proyecto se } \\
\text { ha realizado de forma } \\
\text { brillante. }\end{array}$ & $\begin{array}{l}\text { La dirección del proyecto } \\
\text { ha sido aceptable. }\end{array}$ & $\begin{array}{l}\text { La dirección del proyecto es } \\
\text { mejorable. }\end{array}$ & $\begin{array}{l}\text { La dirección del proyecto no } \\
\text { ha existido. }\end{array}$ & \\
\hline $\begin{array}{l}\text { DURACIÓN DEL } \\
\text { VIDEO }\end{array}$ & $\begin{array}{l}\text { La duración del vídeo se } \\
\text { ajusta a los límites } \\
\text { establecidos. }\end{array}$ & $\begin{array}{l}\text { La duración del vídeo } \\
\text { supera los límites } \\
\text { establecidos en un 25\%. }\end{array}$ & $\begin{array}{l}\text { La duración del vídeo supera } \\
\text { los límites establecidos en } \\
\text { un } 50 \% .\end{array}$ & $\begin{array}{l}\text { La duración del vídeo supera } \\
\text { los límites establecidos en un } \\
75 \% \text { o no llega a los mínimos } \\
\text { establecidos. }\end{array}$ & \\
\hline
\end{tabular}

Rúbrica para proceso aprendizaje cooperativo- video Química General II Prof. Sergio Armenta

Grupo

\begin{tabular}{|c|c|c|c|c|c|}
\hline CATEGORIA & 4 & 3 & 2 & 1 & NOTA \\
\hline $\begin{array}{l}\text { PARTICIPACIÓN } \\
\text { GRUPAL }\end{array}$ & $\begin{array}{l}\text { Todos los estudiantes } \\
\text { cooperan con entusiasmo }\end{array}$ & $\begin{array}{l}\text { Al menos } 3 / 4 \text { de los } \\
\text { estudiantes cooperan }\end{array}$ & \begin{tabular}{|l|} 
Al menos la mitad de los \\
estudiantes presentan ideas \\
propias
\end{tabular} & $\begin{array}{l}\text { Sólo una participa } \\
\text { activamente }\end{array}$ & \\
\hline $\begin{array}{l}\text { RESPONSABILIDAD } \\
\text { COMPARTIDA }\end{array}$ & $\begin{array}{l}\text { Todos comparten por igual la } \\
\text { responsabilidad sobre la } \\
\text { tarea }\end{array}$ & $\begin{array}{l}\text { La mayor parte de los } \\
\text { miembros del grupo } \\
\text { comparten la } \\
\text { responsabilidad en la tarea }\end{array}$ & $\begin{array}{l}\text { La responsabilidad es } \\
\text { compartida por } 1 / 2 \text { de los } \\
\text { integrantes del grupo }\end{array}$ & $\begin{array}{l}\text { La responsabilidad recae en } \\
\text { una sola persona }\end{array}$ & \\
\hline $\begin{array}{l}\text { GESTIÓN DE LOS } \\
\text { CONFLICTOS }\end{array}$ & $\begin{array}{l}\text { Los conflictos surgidos } \\
\text { durante el proyecto se han } \\
\text { resuelto correctamente con } \\
\text { la participación de todos los } \\
\text { miembros. }\end{array}$ & $\begin{array}{l}\text { Algunos conflictos surgidos } \\
\text { durante el proyecto se han } \\
\text { resuelto correctamente } \\
\text { con la participación de } \\
\text { todos los miembros. }\end{array}$ & \begin{tabular}{|l|} 
Algunos conflictos surgidos \\
durante el proyecto se han \\
resuelto correctamente \\
pero sólo por la implicación \\
de algún individuo.
\end{tabular} & $\begin{array}{l}\text { No se han resuelto los } \\
\text { conflictos. }\end{array}$ & \\
\hline $\begin{array}{l}\text { DISTRIBUCIÓN DE } \\
\text { LAS TAREAS }\end{array}$ & $\begin{array}{l}\text { Cada estudiante tiene una } \\
\text { tarea definida y la } \\
\text { desempeña correctamente. }\end{array}$ & $\begin{array}{l}\text { Cada estudiante tiene una } \\
\text { tarea asignada, pero no } \\
\text { está claramente definida o } \\
\text { no es consistente. }\end{array}$ & \begin{tabular}{|l|} 
Hay tareas asignadas a los \\
estudiantes, pero los \\
estudiantes no las realizan.
\end{tabular} & No se asignan tareas. & \\
\hline $\begin{array}{l}\text { PLANIFICACIÓN DE } \\
\text { LAS TAREAS }\end{array}$ & $\begin{array}{l}\text { Las tareas se planifican } \\
\text { adecuadamente y se } \\
\text { realizan de acuerdo con el } \\
\text { cronograma. }\end{array}$ & $\begin{array}{l}\text { Las tareas se planifican } \\
\text { adecuadamente pero no } \\
\text { se realizan de acuerdo con } \\
\text { el cronograma. }\end{array}$ & $\begin{array}{l}\text { Las tareas no se planifican } \\
\text { adecuadamente. }\end{array}$ & $\begin{array}{l}\text { No hay cronograma ni } \\
\text { planificación }\end{array}$ & \\
\hline
\end{tabular}

Fig. 2 Rúbricas utilizadas durante la evaluación del proceso y del producto en la elaboración de microvideos en la asignatura Química General II, siendo el 4 una calificación excelente y el 1 insuficiente.

Finalmente, los alumnos han realizado un total de 8 microvideos; 2 del tema 1 (Energía de las reacciones químicas), 1 del tema 2 (La dirección del cambio químico), 1 del tema 3 (El equilibrio en las reacciones químicas), 1 del tema 4 (Cambios de estado de sustancias

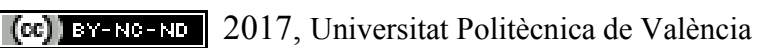


puras), 1 del tema 5 (Disoluciones), 1 del tema 6 (Equilibrio ácido-base) y otro del tema 7 (Equilibrios de formación de complejos).

A modo de ejemplo, en la Tabla 1 se muestra el resumen de las puntuaciones obtenidas por los diferentes grupos en las rúbricas de objeto (microvideos). Las notas de los alumnos corresponden a la media de las valoraciones del resto de grupos obtenida por cada grupo en cada categoría.

Tabla 1. Resumen de las puntuaciones obtenidas en las rúbricas-objeto por los diferentes grupos de alumnos.

\begin{tabular}{|c|c|c|c|c|c|c|c|c|c|}
\hline Alumnos & Gr.1 & Gr.2 & Gr.3 & Gr.4 & Gr.5 & Gr.6 & Gr.7 & Gr.8 & \\
\hline Categoría & $\begin{array}{c}\text { Nota } \\
\text { media }\end{array}$ & $\begin{array}{l}\text { Nota } \\
\text { media }\end{array}$ & $\begin{array}{c}\text { Nota } \\
\text { media }\end{array}$ & $\begin{array}{c}\text { Nota } \\
\text { media }\end{array}$ & $\begin{array}{l}\text { Nota } \\
\text { media }\end{array}$ & $\begin{array}{c}\text { Nota } \\
\text { media }\end{array}$ & $\begin{array}{l}\text { Nota } \\
\text { media }\end{array}$ & $\begin{array}{c}\text { Nota } \\
\text { media }\end{array}$ & Media \\
\hline $\begin{array}{l}\text { Conceptos } \\
\text { teóricos }\end{array}$ & 3,7 & 2,9 & 3,7 & 4,0 & 4,0 & 3,3 & 3,4 & 3,7 & 3,6 \\
\hline $\begin{array}{l}\text { Edición del } \\
\text { video }\end{array}$ & 3,3 & 2,7 & 3,3 & 3,9 & 3,3 & 2,7 & 3,3 & 3,5 & 3,2 \\
\hline Guión & 3,0 & 2,9 & 3,0 & 3,6 & 3,7 & 2,7 & 3,1 & 3,7 & 3,2 \\
\hline Dirección & 3,4 & 3,1 & 3,4 & 3,7 & 3,6 & 2,7 & 3,3 & 3,8 & 3,4 \\
\hline $\begin{array}{l}\text { Duración del } \\
\text { video }\end{array}$ & 3,0 & 4,0 & 3,9 & 3,9 & 2,7 & 3,7 & 3,6 & 4,0 & 3,6 \\
\hline \multicolumn{10}{|l|}{ Profesor } \\
\hline Categoría & Nota & Nota & Nota & Nota & Nota & Nota & Nota & Nota & Media \\
\hline $\begin{array}{l}\text { Conceptos } \\
\text { teóricos }\end{array}$ & 3 & 3 & 4 & 4 & 4 & 4 & 3 & 4 & 3,6 \\
\hline $\begin{array}{l}\text { Edición del } \\
\text { video }\end{array}$ & 4 & 2 & 3 & 4 & 3 & 2 & 3 & 3 & 3,0 \\
\hline Guión & 4 & 3 & 3 & 3 & 4 & 2 & 2 & 3 & 3,0 \\
\hline Dirección & 4 & 3 & 4 & 4 & 3 & 3 & 3 & 4 & 3,5 \\
\hline $\begin{array}{l}\text { Duración del } \\
\text { video }\end{array}$ & 2 & 4 & 3 & 3 & 1 & 3 & 2 & 4 & 2,8 \\
\hline
\end{tabular}

Como puede observarse en la Tabla 1, la evaluación por parte de los alumnos ha sido bastante similar a la proporcionada por el profesor, lo que indica cierto grado de validez en la forma de evaluar y al mismo tiempo se les hace participes de esta etapa del proceso enseñanza/aprendizaje.

Indicar que la nota media obtenida por los alumnos para la rúbrica-objeto fue de 3.3 (8.2), mientras que para la rúbrica-proceso fue de 3.5 (8.8), siendo el valor global de 3.4 (8.5).

De forma adicional, se les pasó una encuesta a los estudiantes para evaluar el grado de satisfacción con la actividad realizada. Las preguntas de la encuesta junto con los porcentajes de respuestas se puede observar en la Tabla 2. 
Tabla 2. Porcentaje de respuestas obtenidas en la encuesta realizada sobre la actidad (número de encuestas 33).

\begin{tabular}{|c|c|c|c|c|}
\hline & Nunca & $1 \mathrm{vez}$ & $1-10$ veces & mas de 10 \\
\hline $\begin{array}{c}\text { ¿Has realizado algún tipo de } \\
\text { trabajo audiovisual } \\
\text { previamente? }\end{array}$ & 42 & 15 & 42 & 0 \\
\hline & $<\mathbf{2 h}$ & $2-5 h$ & $5-10 h$ & $>10 h$ \\
\hline $\begin{array}{l}\text { ¿Cuánto tiempo has dedicado } \\
\text { a la realización de vídeo? }\end{array}$ & 3 & 42 & 33 & 21 \\
\hline & $\mathbf{S i}$ & No & NS/NC & \\
\hline $\begin{array}{l}\text { ¿Has participado en todas las } \\
\text { tareas necesarias para realizar } \\
\text { el vídeo? }\end{array}$ & 67 & 24 & 9 & \\
\hline & Casa & Aula & Biblioteca & Otros \\
\hline $\begin{array}{c}\text { ¿Dónde se han realizado } \\
\text { mayoritariamente las sesiones } \\
\text { de preparación de los } \\
\text { microvídeos? }\end{array}$ & 56 & 0 & 44 & 0 \\
\hline & Libro & Internet & $\begin{array}{c}\text { Apuntes de } \\
\text { clase }\end{array}$ & Otros \\
\hline $\begin{array}{l}\text { ¿Qué tipo de material } \\
\text { bibliográfico se ha empleado } \\
\text { en la preparación del } \\
\text { contenido del vídeo? }\end{array}$ & 8 & 34 & 58 & 0 \\
\hline & Telefono movil & Tableta/iPad & Ordenador & Otros \\
\hline $\begin{array}{c}\text { ¿Desde qué dispositivo se ha } \\
\text { editado el vídeo? }\end{array}$ & 14 & 9 & 77 & 0 \\
\hline & $\begin{array}{c}\text { Totalmente de } \\
\text { acuerdo }\end{array}$ & De acuerdo & $\begin{array}{c}\text { En } \\
\text { desacuerdo }\end{array}$ & $\begin{array}{c}\text { Muy en } \\
\text { desacuerdo }\end{array}$ \\
\hline $\begin{array}{l}\text { ¿Crees que el microvídeo te } \\
\text { ha ayudado a comprender } \\
\text { mejor está tema de la } \\
\text { asignatura? }\end{array}$ & 36 & 55 & 9 & 0 \\
\hline $\begin{array}{l}\text { ¿Crees que el microvídeo ha } \\
\text { ayudado a comprender mejor } \\
\text { o recordar este tema de la } \\
\text { asignatura a tus compañeros? }\end{array}$ & 21 & 70 & 9 & 0 \\
\hline $\begin{array}{l}\text { ¿Crees que el microvídeo de } \\
\text { otros compañeros te ha } \\
\text { ayudado a comprender el resto } \\
\text { de Temas de la asignatura? }\end{array}$ & 27 & 61 & 12 & 0 \\
\hline $\begin{array}{c}\text { ¿Crees que la visualización de } \\
\text { los vídeos realizados te ha } \\
\text { ayudado a mejorar los } \\
\text { conocimientos de la } \\
\text { asignatura? }\end{array}$ & 6 & 82 & 12 & 0 \\
\hline $\begin{array}{l}\text { ¿Cuál ha sido tu grado de } \\
\text { satisfacción con las actividades } \\
\text { de microvídeos propuesta? }\end{array}$ & 15 & 55 & 30 & 0 \\
\hline
\end{tabular}

Como puede observarse en los resultados de la encuesta realizada, la mayoría de los estudiantes, entre el 88 y el $91 \%$ (totalmente de acuerdo y de acuerdo), considera que la actividad les ha sido útil a ellos mismos y al resto de sus compañeros para comprender 
mejor los conocimientos de la asignatura. Sin embargo, este porcentaje disminuye al $70 \%$ cuando se les pregunta por el grado de satisfacción con la actividad propuesta, probablemente debido al tiempo que implica el desarrollo de la actividad.

\section{Conclusiones}

Como conclusión, la experiencia ha resultado muy positiva, tanto para los alumnos como para el profesorado.

Al haber una participación íntegra de todos los representates del grupo (el $67 \%$ de los estudiantes afirman que han participado en todas las actividades), se fomenta el trabajo en equipo y el interés por la experiencia de todos los miembros del grupo. Con la actividad propuesta, se fomenta el interés por la asignatura, se repasan los apuntes, y se refuerzan de un forma simple los conceptos mas relevantes del tema.

Los resultados obtenidos son preliminares, por lo que se han obtenido datos de efectividad meramente cualitativos. Para extraer conclusiones mas realistas, se desarrollará esta actividad en cursos futuros así como se usarán grupos control en los que no se aplique esta herramienta. De esta forma se podrá evaluar cuantitativamente su impacto a largo plazo en el proceso de enseñanza/aprendizaje de los alumnos.

\section{Referencias}

Allam, C., (2006) "Using filmmaking to teach students about Shakespeare, urban regeneration and other stuff”, DIVERSE Conference, Glasgow.

EDTECH MAGAZINE, Akanegbu, A. Vision of Learning: A History of Classroom Projectors, $<$ http://www.edtechmagazine.com/k12/article/2013/02/vision-learning-history-classroom-projectors $>$ [Consulta: 28 de marzo de 2017]

GARDNER, H. (1983) Frames of mind: the Idea of multiple intelligence, New York, Basic Books. 